\title{
Stakeholder Perception of the Impacts of Communication for Development in NGO-Supported Organizational Capacity Building: A Case of Yobe State Primary Health Care Management Board
}

\author{
Adamkolo Mohammed Ibrahim* Danjuma Gambo \\ Department of Mass Communication, University of Maiduguri, PMB 1069, Borno State, Nigeria
}

\begin{abstract}
Utilization of communication for development (C4D) in organizational capacity-building support provided by foreign aid-assisted developmental programs run by non-governmental organization (NGOs) has been shown to improve primary health care (PHC) services in both urban and rural communities, especially the latter. This study investigated stakeholder perceived benefits of organizational capacity-building support provided by NGOs toward the improvement of PHC services in Yobe State. Adopting a case study approach with key informant interview (KII), the responses of four key management staff of Yobe State Primary Health Care Management Board (YSPHCMB) were captured and analyzed using the organizational capacity assessment tool model and critical discourse analysis. The key findings revealed that two critical C4D techniques namely, advocacy and behavior-change communication have impacted significantly toward the strengthening of both YSPHCMB and improvement of PHC services in rural areas of the state more than it did in urban centers; organizational capacity-building support provided by NGOs have significantly strengthened the capacity of YSPHCMB effectively more than both the State and Federal Governments (the primary funders of PHC services) did; and perceived sustainability crisis (PSC) in the event of the expiration of the tenure of some NGOs and developmental programs has been identified as a critical challenge that may affect the tremendous successes achieved by the programs/NGOs negatively should they close as anticipated. To avert the occurrence of PSC in the aftermaths of the closure of an NGO, both the State and Federal Governments should ensure enough and timely release of PHC counterpart funding.
\end{abstract}

Keywords: C4D, communication for development, Nigerian primary health care services, NGO, OCAT, organizational capacity assessment tool, PHC,

DOI: $10.7176 / \mathrm{NMMC} / 79-04$

Publication date: April $30^{\text {th }} 2019$

\section{Introduction}

Located in the Sahel Savannah zone in north-eastern Nigeria, Yobe State is largely rural and one of the poorest states in the country. The health service system in the state is split into three sub-systems (or, sub-sectors), namely Yobe State Ministry of Health (YSMOH), Yobe State Hospitals Management Board (YSHMB) and Yobe State Primary Health Care Management Board (YSPHCMB), which is responsible for the management of all activities involving primary health care services provision in the state including coordinating the activities of Primary Health Care (PHC) facilities (The World Bank 2016c; Vanguard 2016). Managed by PHC coordinators, PHC facilities are distributed across the 17 Local Government Areas (LGAs) of the state. The PHC coordinator are saddled with the responsibility of coordinating PHC activities in their respective LGA. For management purposes, the LGAs are fragmented into six health zones with a zonal officer in charge of the coordination of health activities in each zone (Adeniyi et al. 2001; Chibuzor 2018; NPHCDA 2017; YSMOH 2014).

YSHMB is statutorily mandated to manage the affairs of all secondary health care facilities in the state are while YSMOH focuses on the coordination of the activities of department and agencies under its jurisdiction and formulation of policies and strategies for the entire health sector in the state (Vanguard 2016). Of the total of 517 health facilities in the state, 504 are categorized as primary, 12 as secondary and two as tertiary (YSMOH 2014). Similarly, at the national level, the Nigerian health system operates primary health care at the Local Government level, secondary health care at State level and tertiary health care at Federal level. The Nigerian Federal Ministry Health (FMOH, 2017) defines PHC as "the main focus for delivering effective, efficient, quality, accessible and affordable health services to a wider proportion of the population "(p. 33). At the national level the National Primary Health Care Development Agency (NPHCDA) takes care of the provision of support for the implementation of PHC service in the country (Adeniyi et al. 2001; Chibuzor 2018; The World Bank 2016d).

This study adopted an organizational capacity assessment tool (OCAT) to gauge stakeholders' perception of what it considers to be the model of what it should be, and how it measures up in terms of organizational capacity building and technical assistance. This OCAT enables organizations such as YSPHCMB to identify their strengths and weaknesses against this model as an important first step in diagnosing the reasons for these strengths and weaknesses, and in planning for the technical, managerial or organizational development 
interventions which are required to improve their organizational capacity (FMOH 2010). It is not, by any means, the only tool for this purpose, but has proven itself useful in several countries in the world and is offered for local modification. It is based on the idea that there are many common denominators in the organizational components of technical boards partnering with non-governmental organizations (NGOs), together with some local variations (Booth, Ebrahim, \& Morin 1998; Brown \& Leigh 1996).

It is usual for NGOs to look at government organizations, or ministries, departments and agencies (MDAs) as vehicles for project implementation. In such cases, the developmental capacity-building intervention providing NGO is interested in whether the MDA can carry out the project under discussion, and therefore, it will try and ascertain the capacities of the MDA in relation to that project (The World Bank 2017). Organizational communication and behavior scholars have criticized this practice and encouraged rather the development of MDAs as organizations which may be able to handle a variety of projects over time and may be able to develop its own programs and projects once the capacity-building activity (and project funding) under discussion is completed. Moreover, assessing the capacity of an MDA to carry out a project may not give the NGO providing the capacity-building support a rounded understanding of the MDA's competence when it may well have other NGOs who are asking it to carry out other projects at the same time (FMOH 2010; NPHCDA 2017).

Government ministries, departments and agencies (MDAs) are also interested in their own organizational development, in their own progress towards organizational competence and sustainability. They want to develop beyond the requirements that an NGO has of them for a project. While those interested in the organizational development of MDAs can diagnose strengths and weaknesses of an MDA by a participatory research, enquiry and investigation process, this process is limited by the lack of an agreed model of what an ideal MDA should look like. In many cases in Africa, there is not a long history of NGOs, and no established tradition of the roles and responsibilities of NGOs (Brown \& Leigh 1996; The World Bank 2017). In addition, there is often increasing pressure from governments and donors to push MDAs into particular roles. An important part of organizational capacity assessment (OCA) is to establish the model against which an organization's capacity is assessed. Both donors and MDAs should, therefore, have an interest in developing an understanding of the parameters of a complete and healthy MDA. There is great value in a tool which will help them to understand the elements of an MDA with well-rounded capacity (Booth et al. 1998; FMOH 2010; UNFPA 2015).

This article reports the findings of a case study of YSPHCMB with the main objective of determining the impacts of organizational capacity-building support provided by NGOs for the purpose of developing PHC service delivery in the state from the perspective of the following indicators, namely organizational governance, coordination and partnerships, organizational planning and budgeting, resource mobilization and management board using key informant interview (KII) perspective. The study was premised on the notion of communication for development (C4D) from two perspectives of C4D, namely communication for advocacy and strengthening an enabling communications environment (see UNDP, 2011). The specific objectives are to: (i) gain perspectives from a stakeholder group seen as having an important role in providing useful, critical information about the performance output of YSPHCMB with regard to NGO-assisted capacity building and (ii) gain information in specific areas where key informants are likely to have specialized knowledge, especially regarding the relationship between administration and quality service delivery in PHC services in the state. It is presumed that in providing greater depth, the results have the potential to add caveats and explanation to instances of 'success' or 'failure' detected with the instruments. In addition, by using respondents' own words, the KII gives a 'human face' to the findings.

\section{Literature Review}

\subsection{The State of Primary Health Care Services in Yobe Sate}

Despite significant investments in the state health sector over the years, available records show that the health care system in the state is weak, especially primary health care services. An issue that is attributed to the State Government's inability to provide basic health care services for the prevention, management and control of common community health problems, especially those related to primary health care leading to poor health indices in the state (UNESCO 2007). For example, available C4D data show that the maternal mortality ratio in the state is estimated at $1200 / 100,000$ live births, infant mortality is $105 / 1000$ live births and child mortality is 178/1000 live births (The World Bank 2016a\&b). Additionally, according FMOH (2017) only 29.8\% of all PHC centers in the state, $36.7 \%$ of all PHC facilities in the north-east region and $29.7 \%$ of all PHC centers in the entire country have basic medical equipment (Chibuzor 2018). According to YSMOH (2015), the State Government:

declared a state of emergency in the health sector following observation of the numerous challenges facing it. Hitherto, several measures have been adopted to address the chronic manpower shortages amongst which are; automatic upgrading of newly qualified indigenous medical doctors to the consolidated medical salary scale (CONMESS 01) from the students GL-7 
scale, the contracting of 11 medical consultants from various specialties on weekly visitations to the state specialist hospital Damaturu, contracting of foreign based medical doctors, massive employment of nurses and midwives and other health care professionals. (P. 11)

Furthermore, in the last couple of years, the Yobe State Governor, Alhaji Ibrahim Gaidam has redoubled his administration's efforts toward reviving the paralyzed health sector infrastructurally by upgrading of the five major secondary health facilities in the state, renovating and equipping of several others, training of personnel and the completion and commissioning of the Yobe State University Teaching Hospital in Damaturu. Prior to that development, however, the state had suffered acute lack of health services delivery facilities and equipment, with most of the public health facilities, particularly PHC centers being dilapidated and poorly equipped (Chibuzor 2018; FMOH 2010; The World Bank 2016c\&d). For example, the findings of a national survey of public PHC facilities in the country showed that, "only a quarter of health facilities in Nigeria had more than $50 \%$ of the minimum service package and $40 \%$ had less than a quarter" (YSMOH 2014, p. 10); and that, of the 517 health care facilities in the state, only 335 were functional (Chibuzor 2018).

Health care is a labor-intensive system that requires different skill-mix, notably medical doctors, nurses and midwives, community health extension workers (CHEWs), office administrators and even cleaners. So is C4D. Hence, as welcome as infrastructural development is, by no means can one say that it is the alpha and omega of overcoming the myriad of challenges the PHC sector faces. Available C4D records indicated inadequacy of trained and skilled health care service providers, poor and delayed funding and budgeting, lack of professionalization, poor resource mobilization, poor planning and poor governance are highlighted as some of the major constraints of the PHC in the state (NPHCDA 2017; The World Bank 2016a\&b). Additionally, failure to link policy to planning and budget, making policy decisions without considering expenditure implication which enforces expenditure without changing the policy that drives the required expenditure, obsolete budget process system of proper planning and cost effective analysis of projects and lack of institutionalized system of performance and expenditure review to provide evidence for policy planning have been shown to pose major challenges to quality PHC services provision in the state (Melkote \& Steeves 2001; YSMOH 2014).

However, with less than $50 \%$ of the population of the state having access to quality health care services and poor health indices, the need for effective partnerships cannot be overemphasized especially with the high financial investments for infrastructural and human resource development by the State Government (The World Bank 2016a\&b). With Yobe being a poor state, it is glaring that the State Government cannot bear this burden alone. As a matter of fact, the state is yet to meet the $15 \%$ national health budget recommendation, e.g., only $7.6 \%, 13 \%$ and $12 \%$ of the 2014,2011 and 2019 budgets respectively were voted for health sector (Chibuzor 2018; YSMOH 2014).

The establishment of effective partnerships with donors, non-governmental organizations (NGOs) and other funders is a priority for obvious reasons (Brown \& Leigh 1996). However, the following challenges are identified by YSMOH (2014) as capable of marring smooth partnerships:

- The lack of clear standards and guidelines for the establishment, coordinating and operationalizing these partnerships

- Because of their profit orientation, private-for-profit organizations have issues with some government policies such as the provision of free services to vulnerable groups

- Because of their mandates and related issues such as the existence of specific targets, not-for-profit partners are coerced to proceed with their programs in order not to affect their performance

- Differing in the funding cycles of some development partners from the government fiscal year, which makes it difficult to align resources

- The current insurgency and security challenges have greatly affected activities of partnerships in the state.

Overall, there is minimal constructive engagement of communities in needs identification, planning and implementation of healthcare programs, which, e.g., often resulted in inappropriate locating of health care facilities and underutilization of the services rendered (UNDP 2011; UNESCO 2007). Data released in a report published by the WHO and the World Bank Group in 2015 showed that, globally, 400 million people lack access to essential health services (The World Bank 2016c\&d; WHO 2015). According to FMOH (2017) and The World Bank (2017) a well-functioning health system ensures the following "building blocks":

- Health service delivery (which includes a well-maintained infrastructure)

- Human resources for health (trained and motivated health workers)

- Health information systems (good accountability and reporting, e.g., C4D)

- Pharmaceutical management (a reliable supply of medicines and technologies)

- Health financing (adequate funding)

- Leadership and governance (strong health plans and evidence-based policies

A performance review at the end of the MDGs in 2015 indicated a slow progress, particularly regarding 
health-related goals of reducing maternal and child mortality and eliminating HIV/AIDS in the state (The World Bank 2016a\&b).

2.2 Communication for Development (C4D)

Communication is vital for human development. Communication processes are central to broader empowerment practices through which people can arrive at their own understanding of issues, to consider and discuss ideas, to negotiate, and to engage in public debates at community and national levels (UNDP, 2011). It is the role of Communication for Development in empowerment processes that helps distinguish C4D from other forms of communication (The World Bank 2007). The empowerment-related role of C4D makes it a vital element in programming efforts aimed at achieving the Millennium Development Goals and other development priorities (Melkote \& Steeves, 2001; UNESCO, 2007). Cited in UNDP (2011), in 1997, through Article 6 of United Nations General Assembly Resolution (UNGAR) 51/172, the UN adopted the following formal definition of Communication for Development, "communication for development stresses the need to support two-way communication systems that enable dialogue and that allow communities to speak out, express their aspirations and concerns and participate in the decisions that relate to their development" (p. 1).

Since then, other definitions of C4D have been advanced that reflect increased understanding of the role of C4D in development processes (UNESCO, 2007). In 2006, the Rome Consensus from the World Congress on Communication for Development cited in UNDP (2011) The World Bank (2007) defined Communication for Development as:

... a social process based on dialogue using a broad range of tools and methods. It is also about seeking change at different levels, including listening, building trust, sharing knowledge and skills, building policies, debating and learning for sustained and meaningful change. It is not public relations or corporate communications. (P.1)

Communication for Development (C4D) makes a difference to human development. C4D prioritizes communication systems and processes that enable people to deliberate and speak out on issues important to their own well-being (Melkote \& Steeves 2001; UNFPA 2015). Its role in empowerment processes helps distinguish Communication for Development from other forms of communication, for example, corporate and internal communications, and makes it an essential part of programs aimed at achieving the Millennium Development Goals (MDGs) and other development priorities in an equitable and sustainable manner, especially those related to PHC services both at social and organizational levels (FMOH, 2017; Melkote \& Steeves, 2001; UNESCO, 2007).

\subsection{Organizational Capacity Assessment Tool: Theoretical Perspective}

\subsubsection{The notion of organizational capacity development}

Organizational development based on OCA is an ongoing process that optimises an organization's performance in relation to its goals, resources and environment. It addresses change within the organization itself, even when these changes are meant to help in the development of its own institutionalization (Kabo et al. 2018; USAID 2012). YSPHCMB as an organization in charge of maternal and child healthcare services provision and administration needs to be aware that institutions transcend individual organizations and require different goals, strategies, time scales and tools to bring about the desired change (Breuer, Lee, De Silva, \& Lund 2016; BioMed Central 2013; Booth et al. 1998; Van Iddekinge 2018).

Programs and projects require competent organizations to transform labor, land, resources and technology into ongoing improvements in people's lives. Investment in organizations enables development in other areas. The tools and techniques adopted in this study was aimed at allowing both the capacity-building support providing NGOs (Breuer et al. 2016; Ebensoa et al. 2018), and YSPHCMB to identify current organizational strengths and weaknesses to establish a plan for improvement that includes mechanisms to measure change, successes and failures. Ideally, this will enable the NGOs to contribute to building the organization's capacity as a technical board involved in primary health care development program in the state (Booth et al. 1998; Kabo et al. 2018; YSMOH 2014). Thus, YSPHCMB will then have greater competence in, impact on, and influence over key indicators of OCA and PHC delivery in its own communities, something which is relevant to the lives of the poor and disadvantaged (Adeniyi et al. 2001). A strong organization is essential for the following:

- Cost-effective transformation of inputs into outputs

- Ongoing participation of stakeholders

- Mobilization and regulation of local resources

- Resolution and management of conflicts

- Effective control in the division of benefits

- Monitoring, evaluation and validation of externally supported change

- Translation of government policy into practice

- In more recent times, the empowerment of people to assume some aspects of, and more responsibility 
for, their development, the development of their communities, and the fostering of participatory development.

Government organizations and their leadership, in the process of enhancing their own organizational strengths and those of the sector as a whole will benefit from an understanding of the complementary relationships among organizational development, training/technical assistance, human resource development and the seven components identified by the OCAT - governance, management practices, human resources, financial resources, service delivery, external relations and sustainability (Ebensoa et al. 2018; The World Bank 2017). The primary objectives of the OCAT are to identify organizational strengths and weaknesses at a point in time and then to establish training, technical assistance or other appropriate interventions which will strengthen the overall functioning of the organization in a targeted and systematic process (Brown \& Leigh 1996; Reijseger, Peeters, Taris, \& Schaufeli 2017). The information gathered through use of the OCAT provides data against which an organization's development can be monitored and measured over time (Breuer et al. 2016; Kabo et al. 2018; Kareithi \& Reichert 2012). The critical indicators that this study focuses on are discussed in the paragraphs that follow.

2.3.2 The organizational capacity assessment tool (OCAT)

Organizational assessment may be defined as a tool which can help internal and external evaluators determine how an organization such as is placed compared to a template of 'best practices' for an organization. Such an assessment will allow an organization to identify where it is under-performing and where help is needed. While certain aspects of organizational functioning are common to all MDAs (e.g., competent financial accounting), there is no model template for all MDAs (Breuer et al. 2016; Kabo et al. 2018). The elements of a healthy organization need to be worked out for each country and perhaps for different types of MDAs (such as technical boards, community-based organizations, networks and coalitions) (Reijseger et al. 2017; Van Iddekinge 2018).

This OCAT is not a 'one size fits all' kind of tool, not a panacea for all problems. It is based on a model put forward as a basis for discussion, a model whose elements need to be interpreted and corroborated (or modified) in each case with the organization under assessment (Kabo et al. 2018). Experience has shown that the exercise of deciding what an ideal MDA should look like is a very important learning exercise for the MDA, as important as the subsequent exercise of assessing the organization against the model (Ebensoa et al. 2018). It greatly expands the role of reporting. It more tightly links, unifies and strengthens relationships between monitoring, evaluation and reporting (ME\&R). It also blankets the ME\&R process with a participatory approach (LeMay 2010; Shapiro 2007).

2.3.3 Governance

Governance refers to the leadership and direction of an MDA. Leadership involves articulating and maintaining a vision and mission for the MDA which is shared by the board of directors/trustees or other oversight bodies. The board provides direction, maintains independent oversight of the management, and ensures that effective strategic planning takes place (Kabo et al. 2018). The board can help to identify and procure additional resources for activities, carry out public relations and lobby the government for effective policy development or reform. It can bring additional professional and technical expertise to an MDA by inviting legal, financial, marketing and other technical specialists to join it (Breuer et al. 2016; Ebensoa et al. 2018). Management is responsible for dayto-day operations, ensuring that the MDA implements the policy established by the board. These responsibilities separate the functions of the board and management (LeMay 2010; Van Iddekinge 2018).

Effective leadership fosters the involvement and participation of board members, staff and other stakeholders in all aspects of organizational activities. This is facilitated when board members and communities work together with management and the board to articulate a shared vision of the future, to identify the mission by which they will attain that vision, and to determine realistic and clear objectives (Kabo et al. 2018; USAID 2012; Zimmerman 1995).

\subsubsection{Management practices}

Management practices refer to the mechanisms used to co-ordinate activities and facilitate processes within the organization. These practices include organizational structure and culture, planning, personnel, program development, administrative procedures, risk management, information systems, budgeting and financial reporting as well as program reporting. Planning must be: (i) long-term, which refers to the process of refining the vision and mission of an organization and determining the long-term strategies needed to achieve its mission; and (ii) short-to-medium term, which refers to the translation of the longer-term strategies into specific objectives for a specified period (LeMay 2010’ Reijseger et al. 2017; Van Iddekinge 2018).

Effective planning requires effective monitoring, evaluation and reporting systems, the outcomes of previous planning, the identification and assessment of resource availability and an understanding of the contextual factors that impact on the organization. Stakeholder involvement enhances planning by benefiting from their insight and helping to ensure their commitment (Riggio 2013; Shapiro 2007). Program or project plans are best implemented when supported by a management plan that identifies requirements for technical assistance (financial, logistical and human resource needs); and budgets and schedules for delivery (Ebensoa et 
al. 2018). Other operating mechanisms which need to be in place are administration of offices and office services; records, cash, equipment and materials; and personnel information. Organizational culture reflects how those who work to achieve its mission perceive, think, feel about and respond to situations affecting the organization's purpose, program and operations (Breuer et al. 2016; LeMay 2010; MSH 2010).

\subsubsection{Human resources}

Human resources refer to all the people connected in any way with the work of the organization. Among these are management, staff, members, communities, funders and board members. These stakeholders should have the motivation, the opportunity and the skills required to contribute in meaningful ways to the organization. Mechanisms for decision making, conflict resolution, communication and meeting protocol are as important as job organization and work allocation (Kabo et al. 2018; Riggio 2013). In mature organizations, job descriptions and task assignments are updated to match changing plans, priorities and conditions. Work is allocated to ensure co-ordination, communication and smooth work flow. Staff and communities are asked to perform tasks that fit their skills and expertise (Breuer et al. 2016). Opportunities to upgrade skills or develop new ones are provided as these are needed to do the work of the organization. The motivation for people to work in an organization is varied - money, a sense of service, the opportunity to utilize particular skills and interests, religious calling, social status, security, the prospect of travel, power, opportunities for advancement, or a combination of these (Ebensoa et al. 2018; Reijseger et al. 2017; Van Iddekinge 2018).

Organizations must offer a diversity of incentives to reward or sanction performance and they should generally be competitive with the open job market. Staff and stakeholders should be able to use all their skills and experience, if they are to contribute to the organization in a meaningful way and find satisfaction in their work. They should be encouraged to take initiatives to improve the ways in which their work is done. Every organization has an organizational culture. This reflects how those who work to achieve its mission perceive, think, feel about and respond to situations affecting the organization's purpose, program and operations (Kabo et al. 2018; Riggio 2013).

\subsubsection{Financial resources}

An organization's achievements depend, to a large degree, on the resources it has available and how these are managed and applied. A viable organization will initiate systems and procedures to budget regularly to meet financial needs and obligations, to record these financial transactions, and to monitor and report on its financial status. An organization should implement uncomplicated procedures and systems appropriate to its situation (Breuer et al. 2016). Simple mechanisms are enough for organizing cash disbursements and receipts, for maintaining ledgers and bank accounts, and for meeting payroll, petty cash, transport and procurement needs (Shapiro 2007; Van Iddekinge 2018).

Financial systems and procedures should be integrated with the strategic and implementation plans of an organization; they must meet internal requirements as well as those of funders, donors and other development partners. By producing reports and other information in the form and frequency requested by funders, donors and other contributing NGOs and by submitting regularly to independent audits, an organization will demonstrate that it meets these requirements. An organization needs to have a sufficiently diverse resource base and longerterm plan for meeting its financial needs (Ebensoa et al. 2018; Kabo et al. 2018; MSH 2010).

There is a growing awareness among some organizations of the necessity to identify multiple funders and donors, to develop alternative resources within their own communities (such as payment-in-kind, fee-for-service), to form partnerships with the private and NGO sectors and to improve their ability to generate their own funds, all of which will allow them to continue activities when any one source of funding ends. The management of an organization needs to ensure that it follows the legal, fiduciary and labor regulations of its country in a costeffective manner (Breuer et al. 2016). These are some of the same organizational capacities that NGOs should be assisting their target MDAs (such as YSPHCMB) to acquire to ensure long-term sustainability of program services and more independence for the MDA (Ebensoa et al. 2018; Riggio 2013).

2.3.7 Service delivery

An important component for success and effectiveness of an organization is quality service delivery appropriate services provided in a cost-effective way that can be sustained. Sustainability involves the eventual assumption of service-delivery responsibilities by target communities themselves (Reijseger et al. 2017; Van Iddekinge 2018).

\subsubsection{Partnerships and external relations}

An effective organization recognises and responds appropriately to the larger context in which it operates, including the social, political, ecological, economic and other forces which surround it. To build collaborative supportive relationships within the larger context, an organization should become known within appropriate groups within a community; establish a track record of achievements; and widen its impact through partnerships with the government, funder and donor networks and other agencies and MDAs active in the same sectors and geographic areas. This can often be facilitated by building bridges with NGOs, the private sector and the media (Breuer et al., 2016; Kabo et al. 2018; MSH 2010). 
An organization's primary external relationship is with the community it serves by providing services or being an advocate within the larger community. It can increase its effectiveness if it is perceived to be physically and emotionally a part of the larger community. A successful organization should strengthen its relationship with the NGO sector without compromizing its integrity and independence. It should ensure that its activities relate to sectoral coalitions and other bodies or development agencies and the national NGO coalition, and it should respect organizational/NGO legislation. In addition, organizations in collaboration with NGOs should participate in lobbying and advocacy networks to influence legislation and national and regional planning for the benefit of the larger community (Ebensoa et al. 2018; Riggio 2013).

2.3.9 Sustainability

Sustainability refers to the long-term continuation of an organization, program or project. Sustainability results when adequate mechanisms are put in place to maintain the six components - governance, management practices, human resources, financial resources, service delivery and external relations. Program or benefit sustainability occurs when partners and other stakeholders perceive that services are important and of value to them; when they feel a sense of ownership; when program activities can continue because beneficiaries' behavior has changed; or when local institutions have been identified to provide continuing services and support, allowing the organization to develop a phasing-out strategy (Riggio 2013; Wieczorek 2018). Organizational sustainability is based on a shared vision of an organization's mission and expertise, enabling it to interact with other partners in civil society. This is facilitated when an organization is a member of, and shares information with, coalitions and networks, and when it participates fully and equally with other stakeholders in the development process. These activities help to strengthen the NGO sector and the viability of individual organizations (MSH 2010; Silvestri et al. 2018; The World Bank 2017).

\section{Methods}

\subsection{Participants, Procedures and Data Analysis}

The participants were four management staff of YSPHCMB. Targeting at the role they play in the organization, the participants were purposively selected from the organization's four departments, namely human resource, budget, planning and primary health care. The selection was based on the participant's rank and department, i.e., he/she must be a management staff and his/her department must be involved in the provision of services related to any of the indicators outlined under 'development of the question guide' sub-section below. To ensure anonymity and to facilitate smoother data analysis, each participant, or key informant (KI) was assigned a code name (see Lindlof \& Taylor 2002). Because the organization's governing board had been dissolved, the Director in charge of PHC services department responded to questions on governance as well. The participants' ages ranged between 45 and 56 years.

The original data analyzed in this study was captured from four sessions of key informant interview (KII) conducted on 27 September 2018. The KIIs were employed to reveal information from organizational insiders, or stakeholders, i.e., management staff members responsible for policy making and crafting messages and community opinion leaders (Lindlof \& Taylor 2002). Due to logistics reasons the KII was conducted in two places: at YSPHCMB premises and the Emergency Central Office (ECO) both in Damaturu, the capital of Yobe State. The interview session for each participant was conducted separately, and each participant was given a copy of the question guide to go through in order to be familiar with the questions and provide informed responses. Each KII session lasted for approximately 27 minutes. Prior to the actual interview, the researcher engaged each interviewee in a brief conversation on the matter in focus. In addition, the management of YSPHCMB was formerly informed about the study and its objective and formal permission sought and granted at least 24 hours before the interview.

The data was analyzed using the OCAT and critical discourse analysis (CDA) perspective. The OCAT was adopted with modifications from Organizational Capacity Assessment Handbook, PACT Ethiopia Program and Sustainable Development Service Projects, Second Creating Change Strategies for Sustainable Development Workshop, January 14-17, 1997 by the initiatives Project/JSI Research and Training Institute (see also USAID \& MSH 2013 September). CDA is primarily interested and motivated by pressing social issues which can be understood through discourse analysis (van Dijk, 1993). CDA aims at analyzing semiosis, that is, how meaning is created and communicated through written, vocal or sign language. It aims to provide basis for the researcher to understand the dialectical relationships between discourse and other elements of social practices (Lindlof \& Taylor 2002; van Dijk, 1993). The researcher inspected the words in the sentences in order to identify attributes, consequences and values. The interviews were recorded by a note taker and a voice recorder and were then transcribed into text and analyzed.

\subsection{Development of the Question Guide}

Using open-ended questions (see Lindlof \& Taylor 2002), the question guide was designed to gauge the stakeholders' perception of the impacts of NGO-supported organizational capacity-building support (see Kareithi 
\& Reichert 2012) in YSPHCMB on the following indicators:

- Governance, coordination and partnerships

- Planning, budgeting and finance

- Monitoring and evaluation

- Human resource management

- $\quad$ Service delivery

- Infrastructure/facilities provision

- Resource mobilization and PHC funding

\section{Results and Discussion}

4.1 Results

The KII session touched many key issues pertaining to the organizational capacity-building services provided by NGOs pertaining to each of the four key departments in YSPHCMB. Because a large portion of the information provided by the KIs during the interviews were similar, only a summary of the key critical responses for each KI was presented and analyzed.

4.1.1 Key Informant KI-4.P.8.3

This key informant (KI) was asked about the relationships between the mission and vision of YSPHCMB and its and statuary functions and responsibilities; his responses are summarized below:

There are official documents containing the rules and regulations guiding the Board. It used to be governed by a governing board, but now, ever since an ES, or executive secretary was appointed for the Board, it has been dissolved by the State Government. There are hierarchical rules guiding the Board's relationships with donors and other NGOs.... Almost everybody is aware of the mission and vision. It's already pasted on the noticeboard... There is a great deal of coordination in the way we run this organization, especially, PHC, or primary health care service provision to our people and communities.... Whenever we have challenges beyond our control, or noticed something dragging our activities down, we engage the state technical team and partners like MNCH2 [and other NGOs] to discuss challenges identified and proffer solutions to them collaboratively.

The KI was asked regarding the performance of YSPHCMB and his responses are summarized below: YSPHCMB is definitely coming of age, especially with support from [NGOs] because prior to the coming of support from DFID-assisted NGOs, UNICEF-assisted NGOs and Red cross-assisted NGOs such as MNCH2, it wasn't like it is now. There is a great deal of coordination in the way we run this organization, especially, PHC service provision to our people and communities. State technical team engages partners like UNICEF, MNCH2 and other NGOs to discuss challenges identified and proffer solutions to them in the best technical way. So, with the support of NGOs, YSHCMB has been able to achieve a lot of success in advocacy and behavior-change communication (BCC), especially in recent years.

The KI was asked about indicators and YSPHCMB's contribution towards improving PHC in the State and partnerships. He responded, saying:

Before now, the indicators were not as improved as they are now. Rural community PHC indicators are greatly improving. Regarding RI, that is, routine immunization, for example, there is a tripartite agreement with the State Government and other co-partners namely, the Bills and Melinda Gates Foundation and Dangote Foundation which put up a basket fund and make resources available round the clock for improving PHC in the State. We sit down together with our C4D strategists and other stakeholders and plan how to carry out the routine immunization activities using the available data regarding maternal/new-born mortality based on routine immunization supporters' supervision (RISS). Whatever plan we want to execute, or project or activity, we do it in the best practice as supported by NGOs. In fact, one of the NGOs even provides resource mobilization assistance by embarking on infrastructural development and handing them over to the respective benefiting communities. This is very magnanimous of them. All these have greatly helped drop maternal and child mortality rates in this State.

The KI was asked about the issues of demand and supply in urban versus rural communities. His responses are as follows:

We have a national PHC guideline plan. Each ward has functional health facilities working round the clock. We have identified 178 wards in this State, and each of the health facility in these wards serves as referral centre. So, any maternal and child health care issue that comes up there is a network of health facilities that can be reached and accessed by rural communities just like their urban communities. In all these, we had to use C4D techniques, especially advocacy and BCC. 
The KI was asked about gender issues in human resource management, and he responded, saying: Lower rates of educated female persons in the entire State has contributed toward the fewer inclusion of female in the Board. Despite that, however, there are many women working in various capacities, especially in female reproductive health sub-sector there are more female program officers than males. This issue of gender is beyond our capacity for now. However, if there more qualified female applicants, we will employ them, because we have various offices to assign them. In fact, there was a time when we advertized a senior management post slated for female applicants, only two women applied in the whole of the State, and unfortunately, they were not qualified. So, you see, there also the need to re-empower women educationally in this State. We are appealing to the NGOs to intervene pro-actively and instantly, because this is a very critical issue if we want equitable participation of both men and women in the health care development of our State in this $21^{\text {st }}$ Century.

The KI was asked about sustainability of PHC projects in the State; his responses are as follows: I can confidently tell you that with the kind of excellent capacity-building trainings we receive from our partners and NGOs like MNCH2, Nigerian Red Cross, UNICEF, etc., we [YSPHCMB] are not afraid of project or activity or program failure now. Our biggest concern is with sustainability when some of our partners that provide pivotal support to our organization go and leave us, I mean end their program. Such NGOs like UNICEF-assisted ones and MNCH2 should come for the second time. They've been helping us. We are very much satisfied with them. We're lobbying for their coming back.... In YSPHCMB, we conduct monthly validation exercise, month technical meetings, PHC meetings quarterly, and we prioritize C4D in all our activities, and we are achieving good results.

4.1.2 Key Gaps and Recommendations

- There are gaps in demand creation and human resource for health care in some health facilities across the state

- Training and refresher trainings should be done regularly, monthly, quarterly, especially in terms of technology use and application

- More efforts and resource mobilization are required in the area of women empowerment educationally, C4D especially in the area of behavior-change communication (BCC)

- NGOs should continue providing capacity-building support. If the programs' tenure expires, it should be extended.

4.1.3 Key Informant KI-4.F.\&.2

This KI was asked about issues surrounding financial reports and this is what he says:

The State Government appoints an audit to audit. Auditing is done annually, there is quarterly reports of all our financial activities though. Independent bodies do the annual auditing. We face no problem in this regard because everything is going on smoothly and regularly as planned. But our biggest problem of financial or funding of activities is with non-timely release of fund by the State and sometimes, sudden notification of a project but delayed counterpart funding. This is very serious.... We have internal control system.... Coordination and internal communication exist between staff and officers.

The KI was asked about the challenges and constraints of YSPHCMB; his responses are summarized below: Despite highlighting some of the problems/challenges we [YSPHCMB] face, especially pertaining budgeting and financing, in my opinion most of the challenges or problems are from us, the staff and officers of the Board in the State and national body. Can you imagine even the national body of PHC often gives us short notices and deadlines for some projects or activities! They should be informing us for activities very early and give us enough time to plan, request for fund from the State Government and get it approved and released. With this kind of ugly delays, often important maternal and child health care activities go un-executed, which is very bad. This can reverse the success we have already achieved in certain areas, for example in the indicators of RI, or routine immunization. I can confidently tell you again and again that our supporting partners, I mean NGOs, have never failed us in all we do, only we (the PHC body in the State and national body) fail ourselves.

4.1.4 Key Gaps and Recommendations

- Sometimes YSPHCMB faces problems with payment voucher especially in a situation where the payee did not sign the payment voucher and the receipt for the payment; this problem occurs because of the adoption of e-payment. E-payment is excellent and is timely, but it comes with it challenges which the government and NGOs should help overcome this challenge

- Often, bureaucratic delays negatively affect budgeting and financing. The State Government should be releasing fund regularly, advisably, quarterly. 
- Co-partners of YSPHCMB such as donors and funders (NGOs) should advocate for timely release of funds by the government because this is beyond the capacity of YSPHCMB management staff; so, they cannot do anything to avert it. All they could do is to follow up the files, and often, follow-up alone does not yield desired outcome.

- Capacity-building support is always needed, especially with coming technological developments and challenges. YSPHCMB management and staff need more innovative capacity building and technical assistance in communication for advocacy and communication for strengthening an enabling communication environment to catch up with the emerging technological dynamics.

- Capacity building should include all key coordinating/partnering entities such as ministries, boards and agencies (MDAs) or partners in order to ensure continuity of smooth operations and good results

- Management and staff of YSPHCMB need to be educated or enlightened more about work ethics, rules and regulations for them to know the consequences of their actions, either carrot or stick, meaning reward or punishment

4.1.5 Key Informant KI-4.8.R.M

This KI was asked questions regarding human resource performance and plan review. He responded, saying: Most of our critical staff members are punctual. Erring staff members are warned and punished based on the extant civil service rules, and that has improved their performance. It is a known fact that in any organization be it formal or informal, there are effective staff members and ineffective ones. Most of them are punctual and productive even though we a pocket of erring workers. We have put in place a strong machinery for supervision and inspection of our staff members. One female staff from Tarmuwa Local Government health facility absconded duty for about six months. A committee of inquiry was set up to iron out the matter. The committee decided that she either refund the six-month salaries she received, or she work on a half salary for a period of say, one year so that by the end of the year she must have refunded the salaries she enjoyed while absconding work. She agreed to come to work for complete six months (from January 2018 to June 2018) without salary. And, all the money was remitted back to the State Ministry for Local Government and Chieftaincy Affairs. We have sent request for more employees to the State Government, and this has been approved. So, we are now expecting to get about 300 more workers.

The KI was asked about staff training, and he responded as follows:

Everything is going on well. But, often the Director of Human Resource Management is side-lined when it involves recruitment/training.... Our sources for training fund are three: (1) from the Central Government, (2) overhead costs, and (3) collaboration with NGOs. Training is highly needed in order to go along with the dynamic society.

The KI was asked about gender issues in YSPHCMB's personnel; his responses are summarized below: The board gives critical attention to gender issues. But, unfortunately, it seems competently employable female candidates are few in the State because often no competent applicants/candidates are available. Sometimes you would put up advertisement for a particular technical position/rank slated to be occupied by a female staff, and you end up getting applications from only two or one semi-competent or incompetent applicant from the whole State. So, we can't employ incompetent staff. The Board follows civil service rules strictly. Staff recruitment, training, promotion and remuneration are based on professionalism. Salaries, benefits are well paid, regularly as and when due.

4.1.6 Key Gaps and Recommendations

- With this kind of support YSPHCMB receives from NGOs, it is expected that most of its problems and challenges surrounding organizational capacity building can be adequately taken care of. However, YSPHCMB needs to solicit the State Government to lift the embargo on human resource recruitment, especially skilled health workers such as community health extension workers (CHEWS) and junior community health extension workers (JCHEWS) in all the PHC facilities in the state.

- The government should inject more personnel into the system, the output will eventually improve. Especially, since approval for employment of more workers has been given by the government, it should fulfil this pledge as and when due

4.1.7 Key Informant KI-4.P.12.N

This KI was asked questions regarding organizational data management in relation to planning. Below are summaries of some of his key responses:

YSPHCMB has quality data to execute all its planning activities well. Data are collected regularly, and data are processed and analyzed well. Whatever the Board wants to do, the staff in charge would request for the necessary data and we prepare and submit them.

Yes, our staff have been well trained on data management. The NGOs have been very supportive 
to us [YSPHCMB]. Data are collected and processed based on a random selection from across all the health facilities in this State. We ensure safe keeping of all our data and records.

The KI was asked to identify the major constraints YSPHCMB faces, and he responded, saying: Delayed release of funds is our major problem. Since January [2018] up to September [2018] we [YSPHCMB] have experienced delayed capital release from the State Government. The problems can be seen from two angles: (1) delayed fund release and (2) the economic recession. as the latter has been a national problem, the former isn't; it needs to be dealt with squarely for us to work with our partners [NGOS] smoothly. Partners are key and critical to our [YSPHCMB] survival. But they don't give funds, they only support you to conduct your activities. The NGOs for the past six years or so have been supporting us [YSPHCMB] in terms of renovation of facilities, donation of medical equipment; and these have reduced maternal and child mortality rates in the State. Another key challenge of concern is that sometimes our data processing staff notice some errors in the data entry by some staff of some health facilities. This often negatively affects our work. But it can be overcome. May be the NGOs should re-strategize to see how they can build the capacity of our data collectors and processors in all our health facilities. Furthermore, we need our M\&E, that is, monitoring and evaluation to be strengthened. Without strong $M \& E$, no way the Board can function well. We need more funding and capacity building too.

Finally, all the four KIs were asked about the state of C4D in YSPHCMB with respect to the capacity-building support the organization received from NGOs. Their responses were summarized below:

Because Yobe is a rural state, more than 90\% of the PHC program involves the rural populace. And, most of the rural people are illiterate and live in traditional ways. So, for the PHC services provided by YSPHCMB to succeed, communication is very vital. But not all types of communication are relevant here. In this context, we are talking and more concerned about communication techniques that can sensitize the illiterate rural communities to willingly adopt new behaviors capable of reducing diseases and illnesses among them. That is, communication for development, or C4D as it is commonly called. But we [YSPHCMB] cannot achieve this without proper and professional utilization of advocacy communication, i.e., engaging community stakeholders such as traditional and religious leaders with the aim of persuading the populace to accept positive behavior changes for healthy living. Therefore, more than ever before, YSPHCMB needs more support in this aspect because rural people's behavior is a complex phenomenon to control, and new ways of achieving lofty successes with relatively fewer inputs are increasingly evolving nowadays. But, generally, with the invaluable support by our partners [NGOs], we [YSPHCMB] have achieved tremendous successes in C4D especially in rural communities.

4.1.8 Key Gaps and Recommendations

- More training needed on data management and C4D techniques for health workers and community mobilizers

- More, innovative training for M\&E personnel

- Counterpart funds and funds for projects should never be delayed

- MDAs should be trained on the need for timely and regular release of funds

- Personnel need training to consolidate C4D skills and techniques of reaching out to hard-to-reach communities and the illiterate

\subsection{Discussion}

The KII was performed with five management officers of YSPHCMB. Each KI was given a couple of minutes to browse through the question guide prior to commencement of the interview. Each KI was asked questions regarding the impact of NGO-supported organizational capacity building, technical assistance and infrastructural development in areas under the jurisdiction of his department. Most of the Reponses clearly showed that very remarkable improvements have been achieved in the overall operations of the organization, especially in the realms of governance, planning, resource mobilization, coordination, staff capacity building and training, PHC activities, C4D, infrastructure and human resources except for budget and finance which scored lower rating. PHC activities and programs were rated high except when they are linked with financing/funding. In fact, funding (which is largely handled by the State and Federal Governments) was often rated low due to delays, and sometimes absolute non-release of funds, e.g., till after the deadline of the execution of a particular project lapsed. The data indicate that most of the stakeholders expressed utmost confidence with sustainability of all projects, activities, capacity building, infrastructures, etc provided the NGOs, especially MNCH2. However, sustainability was rated extremely low in the event of closure of the NGO-supported programs, especially in the mid- to long-run after the such programs' closure.

Furthermore, the NGOs and both local and international donor organizations have tremendously contributed toward not only building the capacity of YSPHCMB but also fortifying and putting in place mechanism that will 
preserve it for future generations to benefit. Generally, all the indicators were rated excellently well by the stakeholders except for Resource Mobilization and PHC funding indicators. However, the State's commitment toward hitch-free and adequate funding of PHC has been below average. Hence, most of the lapses are attributed to the State (State and/or Federal Governments), with none linked to the NGOs and other supporting partners such as MNCH2 and UNICEF. As a matter of fact, the KII data showed that one of the major supporting NGOs, i.e., $\mathrm{MNCH} 2$ has achieved over $90 \%$ of its program's capacity support activities in YSPHCMB. Therefore, as far as YSPHCMB is concerned, the NGOs have been its biggest supporters, a phenomenon that reduces its perceived sustainability crisis (should some of the NGOs fold up soon). As a matter of fact, without the commitment and support of the NGOs, the State's lackadaisical attitude toward discharging many of its critical responsibilities such as timely release of counterpart funding, advocacy communication, BCC, RI, resource mobilization and service delivery would have been worse than what obtains currently.

Therefore, all that NGOs need to do is to re-strategize by focusing a bit more on enlightening and building the capacity of stakeholders from traditional institutions (traditional rulers, religious leaders) as well as MDAs (rather than members of staff only) using BCC strategies and other relevant methods. In fact, in addition to their being the gate-way into community engagement, traditional/religious leaders can act as not only monitoring and evaluation agents but also survaluation (surveillance and evaluation) agents (see Shapiro 2007). This is largely because traditional leaders are presumed (and should be) apolitical (i.e., they are deemed to not indulge in partisan politics, at least apparently) and are not subject to periodic tenure termination as conventional political leaders are.

The KII data also highlighted significantly the importance of human resource development (e.g., staff training and capacity-building workshops, etc.). All the participants regarded human resource development as a continuous activity that needs to be carried out every so often, especially in order to catch up with the dynamic technological advancements. A further analysis of the data indicated that human resource development (capacity-building/training workshops, etc.) is one of the critical factors capable of guaranteeing sustainability of the support provided by the NGOs in YSPHCMB even if they closed. The NGOs can consider utilizing the human resource development tools in their possession sagaciously to increase the chances of the sustainability of their capacity-building support in YSPHCMB for many more years even after their tenure expires. Frequently carrying out of more of human resource development activities can yield the expected benefits. In all these, strategizing for result-oriented C4D especially in the areas of advocacy communication and BCC in rural communities has been shown to be fundamentally paramount, without which nothing would succeed.

\section{Conclusion}

Sustainability of the developmental capacity-building support provided by the NGOs to YSPHCMB has been one key factor that donors, funders and the NGOs themselves need to consider critically. Skills and techniques of C4D, especially advocacy and behavior-change communication (BCC) have contributed immensely toward community-based PHC services with lesser impacts among urban population. Hence, concerted effort should be made by all stakeholders to address these issues.

The issue of sustainability is gaining increased attention at YSPHCMB especially because some of the developmental intervention programs funded by international development partners, e.g., the Maternal, Newborn and Child Health care program $2(\mathrm{MNCH} 2)$ which is a program funded by the United Kingdom Government's Department for International Development (DFID) and is one of the dedicated NGOs providing capacity-building support to the organization was due to close some time in 2019. Consequently, there has been some disquiet in YSPHCMB over this issue. The data clearly showed that YSPHCMB is pessimistic about its capability to sustain its current organizational capacity in the event that its partnering NGOs, particularly $\mathrm{MNCH} 2$ folds up in 2019. In fact, all the four key informants and other stakeholders stressed the need for $\mathrm{MNCH} 2$ and other NGOs not to be terminated as scheduled and solicited that their tenure be extended.

Therefore, except for the lapses identified in the preceding sections and paragraphs, the capacity-building support provided by the NGOs has tremendously impacted the vast majority of the operations of YSPHCMB: health care service delivery, RI, logistics, resource mobilization, work coordination, data management and planning, budgeting, accounting and financing, staff capacity-building/training, organizational technical assistance and infrastructural development because of improved intra-organizational communication among the various departments and units of YSPHCMB and inter-organizational partnerships with stakeholders, NGOs, donors and communities. However, the stakeholders have indicated that more NGO support is needed in the PHC department of YSPHCMB for smoother execution of policy plans and C4D activities. Some of the key lapses the department suffers include delayed release of funds by the State, bureaucratic hurdles in fund administration and activity planning and inconsistencies in the manner call-for-activity/program information are circulated to affected units.

\subsection{Recommendations}


For the impacts of the capacity-building the NGOs provide at YSPHCMB to be continuously benefited directly by the organization and indirectly by mothers, children and the various health facilities in the state, the issues of sustainability should be treated with paramount importance. On a general note, a large percentage of the capacity-building support the NGOs provided YSPHCMB over the decade or so is perceived capable of standing the test of time, to benefit both the present and future generations of citizens of Yobe State provided the NGOs that are due to close soon (e.g., $\mathrm{MNCH} 2$ ) will extend their program tenure for many more years.

Given the rapid innovations and proliferation of new technologies, gradually staff of YSPHCMB and health workers working in some of the health facilities provided with modern equipment (e.g., those in urban centres) would certainly need more capacity building especially innovative capacity building regarding skills and knowledge about technology use for evidence-based C4D. Of paramount importance is the need for health workers and planning department staff to receive more training on data management.

For the PHC services in the state to be revamped sustainably, MDAs related to health care services in the state should be empowered technically and capacity-wise especially on funding/financing/budgeting in PHC services and the overall operation of YSPHCMB. In collaboration with NGOs, YSPHCMB should mount an advocacy campaign for legislation to criminalize offences related to delayed release or non-release of funds meant for PHC projects or activities. The advocacy should also demand for the creation and activation of a machinery that will be responsible for enforcing the legislative law criminalizing acts related to delayed release of funds for PHC programs.

In order to mitigate the perceived sustainability crisis surrounding the anticipated closure of key partnering in 2019 or not much longer, it is recommended that electronic communication for development (e-C4D) should be adopted especially in the areas of RI in hard-to-reach, remote rural communities during emergencies or epidemics. Concisely, e-C4D can be employed using mobile phones and GSM services a digital system should be designed which will broadcast audio short-message-service (SMS) in local languages to key members of targeted communities, such as heads of household, village heads, word heads, opinion leaders, etc.

\section{References}

Adeniyi. J, Ejembi C.L... et al. (2001), "The Status of Primary Health Care in Nigeria", Report of a Needs Assessment Survey, National Primary Health Care Development Agency, Abuja, Nigeria.

BioMed Central (2013), "Improving Maternal and Child Health Care in Nigeria: An Assessment of the Maternal and Child Care Component of the Subsidy Reinvestment \& Empowerment Program (SURE-p MCH)", Retrieved from http://www.isrctn.com/ISRCTN98056858

Brown, S.P. \& Leigh, T.W. (1996), "A new Look at Psychological Climate and its Relationship to Job Involvement, Effort and Performance", Journal of Applied Psychology 81(4), 358-368. doi: 00219010/96/S3.00.

Chibuzor, O. (2018), “Yobe Proposes N91.6bn Budget for 2019', ThisDay, November 30. Retrieved from https://www.thisdaylive.com/index.php/2018/11/30/yobe-proposes-n91-6bn-budget-for-2019/?amp

Ebensoa, B., Manzanoc, A., Uzochukwub, B., Etiabab, E., Hussa, R., Ensora, T., ... \& Mirzoeva, T. (2018), "Dealing with Context in Logic Model Development: Reflections from a Realist Evaluation of a Community Health Worker Program in Nigeria", Evaluation and Program Planning 73(2019), 97-110. doi: /10.1016/j.evalprogplan.2018.12.002.

FMOH (2017), "National Health Facility Survey 2016 Final Report", Federal Ministry of Health Report, May 2017, Abuja, Nigeria, p. 33.

FMOH (2010), National Strategic Health Development Plan (NSHDP), 2010-2015, Federal Ministry of Health, Abuja, Nigeria.

Kabo, I., Orobaton, N., Abdulkarim, M., Otolorin, E., Akomolafe, T., Abegunde, D., ... \& Sadauki, H. (2018), "Strengthening and Monitoring Health System's Capacity to Improve Availability, Utilization and Quality of Emergency Obstetric Care in Northern Nigeria”, PLoS ONE 14(2), e0211858. doi: 10.1371/journal.pone.0211858.

Kareithi R. \& Reichert K. (2012), "Report on Validating and Weighting the BLC Organizational Capacity Assessment Tool”, MSH, BLC Project, Pretoria, South Africa.

LeMay, N. (2010), "Managing Information: Monitoring and Evaluation (Chapter 8)", In Health systems in Action: An E-Handbook for Leaders and Managers, Cambridge, USA: Management Sciences for Health. Available at https://www.msh.org

Lindlof, T.R., \& Taylor, B.C. (2002), Qualitative Communication Research Methods, Thousand Oaks, CA: Sage. Melkote, S. \& Steeves, H.L. (2001), Communication for Development in the Third World: Theory and Practice for Empowerment, New Delhi: Sage Publications.

MSH, (2010), "Challenges Encountered in Capacity Building: Review of Literature and Selected Tools", Position Paper No 10, April $2010 . \quad$ Retrieved from http://www.msh.org/resourcecenter/publications/challenges-encountered-in-capacity-building.cfm 
NPHCDA (2017), “WHO: Nigeria Midwives Service Scheme”, Retrieved from http://www.who.int/workforcealliance/forum/2011/hrhawardscs26/en/

Reijseger, G., Peeters, M.C.W., Taris, T.W., \& Schaufeli, W.B. (2017), "From Motivation to Activation: Why Engaged Workers are Better Performers", Journal of Business Psychology 32, 117-130. doi: 10.1007/s10869-016-9435-z.

Riggio, R.E. (2013), Introduction to Industrial/Organizational Psychology (6 ${ }^{\text {th }}$ Ed.), New York: Pearson Education, Inc.

Shapiro, J. (2007), Monitoring and Evaluation. Civicus: Johannesburg/Washington. Retrieved from https://www.civicus.org

Silvestri, G., Wittmayer, J.M., Schipper, K., Kulabako, K., Oduro-Kwarteng, S., Nyenje, P., ... \& van Raak, R. (2018), "Transition Management for Improving the Sustainability of WASH Services in Informal Settlements in Sub-Saharan Africa-An Exploration”, Sustainability 10(4052), 1-19. doi: doi:10.3390/su10114052.

The World Bank (2017), "Service Delivery Indicators", Retrieved from http://www.givewell.org/servicedelivery-indicators/March-2015-update\#SDIs_progress

The World Bank (2016a), "Birth and Death Rates, Crude (per 1,000 People): Overview per Country", Retrieved from http://data.worldbank.org/indicator/SP.DYN.CBRT.IN?end=2014\&start=1961

The World Bank (2016b), "Country at a Glance: Nigeria", Retrieved from http://www.worldbank.org/en/country/nigeria

The World Bank (2016c), "Population Density: Overview per Country: Nigeria (People per sq. km of Land Area): Overview per Country: Nigeria", Retrieved http://data.worldbank.org/indicator/EN.POP.DNST?end=2014\&start=1961

The World Bank (2016d), "Population Growth (Annual \%): Overview per Country: Nigeria", Retrieved from http://data.worldbank.org/indicator/SP.POP.GROW?end=2014\&start=1961

The World Bank (2007), World Congress on Communication for Development: Lessons, Challenges and the Way Forward, The World Bank, Washington DC, USA.

UNDP (2011). Communication for Development: Strengthening the Effectiveness of the United Nations, New York, NY: UNDP. Retrieved from www.undp.org/governance

UNESCO (2007), "Towards a Common UN System Approach: The Role of Communication for Development in Achieving the MDGs. UNESCO Background Paper for 10th Inter-Agency Round Table on Communication for Development Round Table", in Towards a common UN System Approach: Harnessing Communication to Achieve the Millennium Development Goals, Paris: UNESCO/UNDP.

UNFPA (2015), "Facility Assessment for Reproductive Health Commodities and Services in Nigeria", 2014 Survey Report, UNFPA February 2015, Abuja.

UNGAR, "United Nations General Assembly Resolution 51/172", Retrieved from http://daccess-ddsny.un.org/doc/UNDOC/GEN/N97/765/67/PDF/N9776567.pdf?OpenElement, p. 1.

USAID (2012), Country Ownership and Organizational Capacity Building: Beyond Principles to Practices, Arlington.

USAID \& MSH (2013 September), "Building Local Capacity for Delivery of HIV Services in Southern Africa Project: BLC Organizational Capacity Assessment Tool User Guide”, United States Agency for International Development and Management Sciences for Health, Washington DC.

Van Dijk, T.A. (1993), "Principles of Critical Discourse Analysis, Discourse and Society 4(2), 249-283. doi: $10.1177 / 0957926593004002006$.

Vanguard (2016), "Only 4\% of Nigerians Covered by NHIS", Vanguard December 2, Retrieved from http://www.vanguardngr.com/2016/12/4-nigerians-covered-nhis/

Van Iddekinge, C.H. (2018), "A Meta-Analysis of the Interactive, Additive, and Relative Effects of Cognitive Ability and Motivation on Performance", Journal of Management 44(1), 249-279. doi: 10.1177/0149206317702220.

Wieczorek, A. (2018), "Sustainability Transitions in Developing Countries: Major Insights and their Implications for Research and Policy”, Environ. Sci. Policy 84, 204-216.

WHO (2015), Media Centre: New Report Shows that 400 Million do not Have Access to Essential Health Services", Retrieved from http://www.who.int/mediacentre/news/releases/2015/uhcreport/en/

YSMOH (2014), "Yobe State Government Health Sector: Medium Term Sector Strategy (Rollover 2015-2017)", Yobe State Ministry of Health report, October 2014, Damaturu, Yobe State, Nigeria, p. 10.

Zimmerman, M.A (1995), "Psychological Empowerment: Issues and Illustrations", American Journal of Community Psychology 25(5), 581-599.

\section{Acknowledgements}

This research was supported by MNCH2 Yobe under the aegis of MannionDaniels West Africa Ltd. We thank 
Alhaji Kaka Gana Mustapha for his moral support.

Authors' Biodata

Adamkolo Mohammed Ibrahim (MSc) is a Lecturer and researcher at the Department of Mass Communication, University of Maiduguri, Borno State, Nigeria. He had his bachelor's degree in Mass Communication from 2002 to 2007 at his Alma Mata department and university. He obtained his MSc Development Communication in 2017 from University Putra Malaysia (UPM). Currently, he is a certified reviewer at Computers in Human Behavior (journal), Elsevier. He is a recipient of Publons 2018 global award for being among the top $1 \%$ of global peer reviewers in communication related to Psychology. His research interests include mass communication and journalism, development communication, social media, cyber bullying, cyber conflict (cyber jihad), ICT4D, information and communication technology (ICT) adoption in agribusiness.

Danjuma Gambo (PhD, Prof.) is a professor of mass communication studies at the Department of Mass Communication, University of Maiduguri, Borno State Nigeria. Currently, he is the Dean, Faculty of Social Sciences of the university. He was the former Director, University of Maiduguri Radio (a.k.a. Unimaid Radio/Kanem FM) and public relations of the university. He teaches mass communication and journalism courses, notably in the areas of news writing and editing and speech and public speaking. Additionally, he is the doyen scholar of development communication at the university. He has published many articles, book chapters and some books. 